\title{
Pars plana incisions of four patients: histopathology and electron microscopy
}

\author{
Frank H Koch, Allan E Kreiger, Manfred Spitznas, Ben Glasgow, Robert Y Foos \\ Marc O Yoshizumi
}

\begin{abstract}
The pathology of pars plana incisions of four patients is described: three with light microscopy and one with light and electron microscopy. Two eyes were removed because of choroidal melanoma, immediately and 8 days after vitrectomy and transvitreous retinal biopsy. Considerable disruption of tissues surrounding the pars plana incisions was observed. Vitreous was incarcerated in the wounds, which healed with granulation tissue. One eye was examined 4 months after vitrectomy for diabetic retinopathy and a failed pars plana filtering operation. It contained fibrovascular ingrowth from all the incisions, infiltrating the vitreous base with granulation tissue and causing vitreous haemorrhage and retinal detachment. One eye was removed 1 year after vitrectomy for anterior hyaloidal fibrovascular proliferation and early phthisis. The wound had fibrous ingrowth histologically and evidence of active fibroplasia.
\end{abstract}

(Br F Ophthalmol 1995; 79: 486-493)

Information regarding the pathology of pars plana incisions is limited. The relation of wound healing to other clinically disruptive fibroplastic processes within the eye, such as fibrous ingrowth, anterior hyaloidal fibrovascular proliferation, and proliferative vitreoretinopathy, is unclear.

Unfortunately, specimens often reach the pathologist late in the clinical course of disease because of enucleation for severe complications of the previous vitrectomy or of the underlying disease. By this stage significant intraocular scarring and anatomical disorganisation may confound interpretation and obscure the histological relations. Furthermore, clinical correlation is often lacking.

This paper reports on the pathological findings in four patients: three studied with light microscopy and one with light and electron microscopy. Two eyes were enucleated soon after the vitreous procedure, another 4 months later, and the last 1 year after vitrectomy. The findings offer some insights into the spectrum of pathological changes that may occur during the healing of sclerotomies.

\section{Material and methods}

PATIENT 1

The patient, a 65-year-old man, was referred with the diagnosis of extramacular disciform degeneration. During follow up the intraocular lesion was observed to grow in size and he underwent biopsy to rule out melanoma.

A standard three port pars plana vitrectomy was performed with the Microvit. Sclerotomies were made with a myringotomy knife and the biopsy was accomplished by passing a 25 gauge needle through the superonasal incision into the tumour and aspirating forcefully. Malignant melanoma of the choroid was found on cytopathological examination. The surgical incisions were closed with interrupted 7-0 polypropylene sutures after careful removal of vitreous from the wounds with cellulose sponges and scissors. The eye was then enucleated immediately (according to the wishes of the patient). The specimen contained a moderate sized, flat, malignant melanoma of the choroid. Following fixation in formalin, the wounds were serially sectioned and examined with light microscopy.

PATIENT 2

The patient, a 26-year-old woman, was first seen at 5 years of age and found to have a normal eye at examination. At age 7 years she was found to have a macular lesion in the right eye which, after extensive consultation, was believed to be a Toxocara granuloma. The lesion was unchanged until age 24 years when it was thought to be enlarging. Observation of the mass over the next year confirmed its growth. The vision dropped to bare light perception because of secondary retinal detachment. Because of concern that the lesion might be malignant, a diagnostic fine needle aspiration was performed.

A standard three port vitrectomy was carried out with the Microvit. Sclerotomies were made with a myringotomy knife. Biopsy of the lesion was accomplished with a 25 gauge needle inserted through the superotemporal sclerotomy in the same manner as in patient 1 . The superior incisions were closed with running 8-0 nylon sutures after meticulous resection of vitreous in the wound with cellulose sponges and scissors. The infusion cannula was withdrawn and the inferotemporal incision was closed with a purse string 6-0 polypropylene suture.

Malignant melanoma of the choroid was established on cytopathological examination of the aspirate. The eye was enucleated 8 days later and fixed in formalin. The specimen contained a moderate sized malignant melanoma of the choroid of mixed cell type in the 


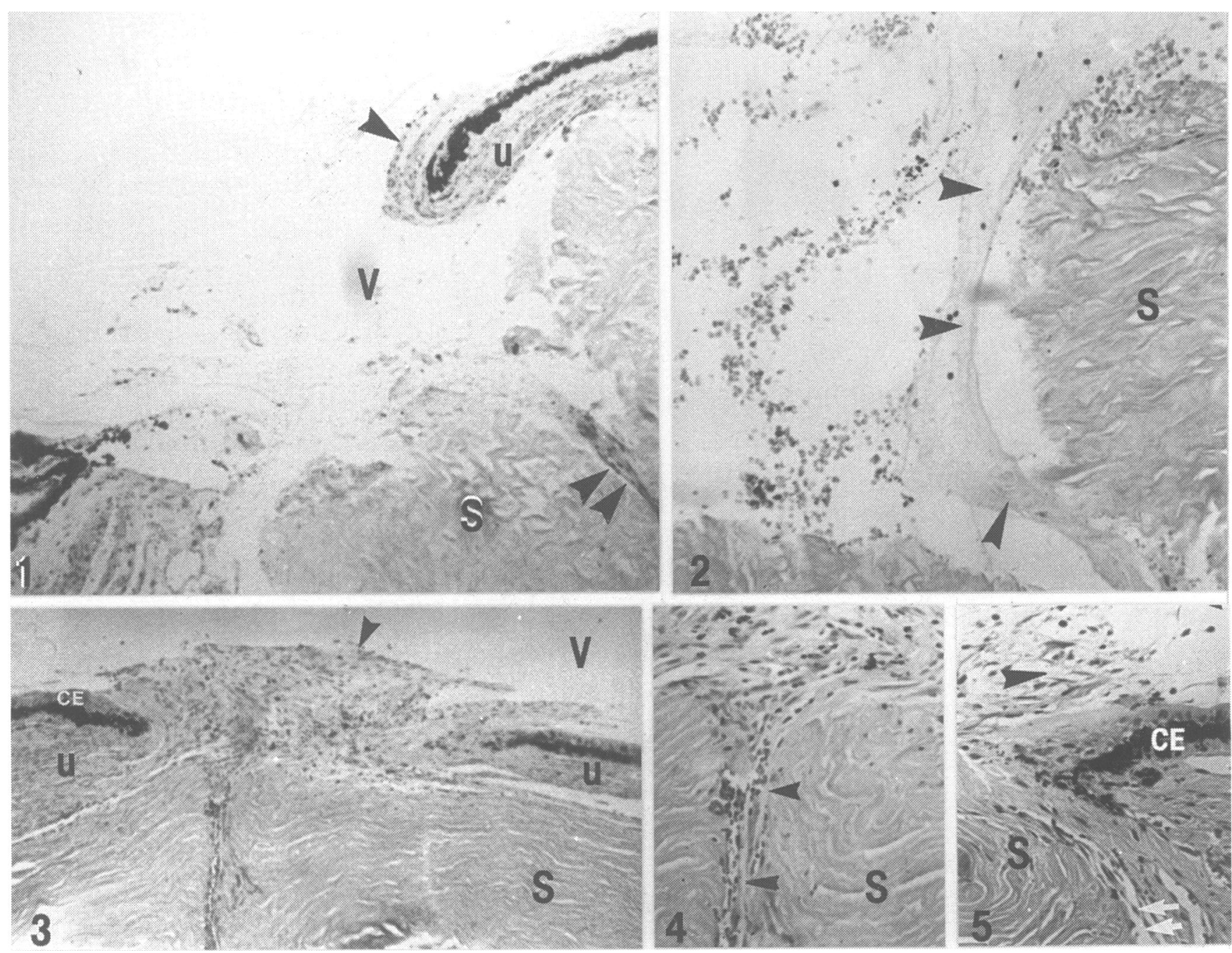

Figure 1 The superotemporal incision of patient 1 showing internal gaping of the scleral wound, and fragmented ciliary stroma prolapsing around the cut edge of ciliary epithelium into the vitreous (arrowhead) and displaced into the closed portion of the scleral wound (double arrowhead). $S=s c l e r a, U=u v e a$, $V=$ vitreous (haiematoxylin and eosin, $\times 200$ ).

Figure 2 The superonasal incision of patient 1 showing vitreous incarcerated in the scleral portion of the incision (arrowheads). S=sclera (haematoxylin and eosin, $\times 550$ ).

Figure 3 The superonasal incision of patient 2 showing gap in ciliary epithelium filled with fibrocellular tissue (arrowhead). $S=s c l e r a, U=u v e a$, $C E=$ ciliary epithelium, $V=$ vitreous (haematoxylin and eosin, $\times 200$ ).

Figure 4 The superonasal incision of patient 2 showing fibrocellular tissue extending into scleral incision (arrowheads). $S=$ sclera (haematoxylin and eosin, $\times 350$ ).

Figure 5 The superotemporal incision of patient 2 showing fibrocellular tissue growing along vitreous fibrils (arrowhead) and into scleral wound (double arrows). $S=$ sclera, $C E=$ ciliary epithelium (haematoxylin and eosin, $\times 350$ ).

posterior pole. The incisions were serially sectioned and examined with the light microscope.

\section{PATIENT 3}

The patient, a 36-year-old white woman with diabetes mellitus, developed vitreous haemorrhage and rubeotic glaucoma bilaterally despite panretinal photocoagulation. She underwent a pars plana vitrectomy, lensectomy, and planned pars plana filtering operation with the Ocutome three port system. The superonasal and inferotemporal incisions were closed with 8-0 nylon. The superotemporal incision was made under a scleral flap as in a trabeculectomy and the opening in the sclera was widened at the end of the procedure with a scleral punch. The scleral flap was then closed over the inner opening.

Postoperatively the intraocular pressure was controlled temporarily; however, the glaucoma returned and the patient developed intractable pain and requested enucleation 4 months later. The eye was fixed in formalin and prepared for light microscopy.

\section{PATIENT 4}

The patient is a 63-year-old man with severe diabetic retinopathy, vitreous haemorrhage, and rubeosis iridis who underwent pars plana vitrectomy with the Microstripper and a three port system. In the immediate postoperative period the patient had recurrent vitreous haemorrhages and lost light perception over several weeks. A diagnosis of anterior hyaloidal fibrovascular proliferation (AHFP) was made clinically. The eye developed phthisis bulbi and required enucleation for pain 1 year after the vitrectomy. The eye was bisected immediately and fixed for electron microscopy by immersion in $2.5 \%$ glutaraldehyde and $2 \%$ paraformaldehyde buffered with $0 \cdot 1 \mathrm{M}$ sodium cacodylate $\mathrm{pH} 7 \cdot 2$. Gross examination revealed a total retinal detachment with 

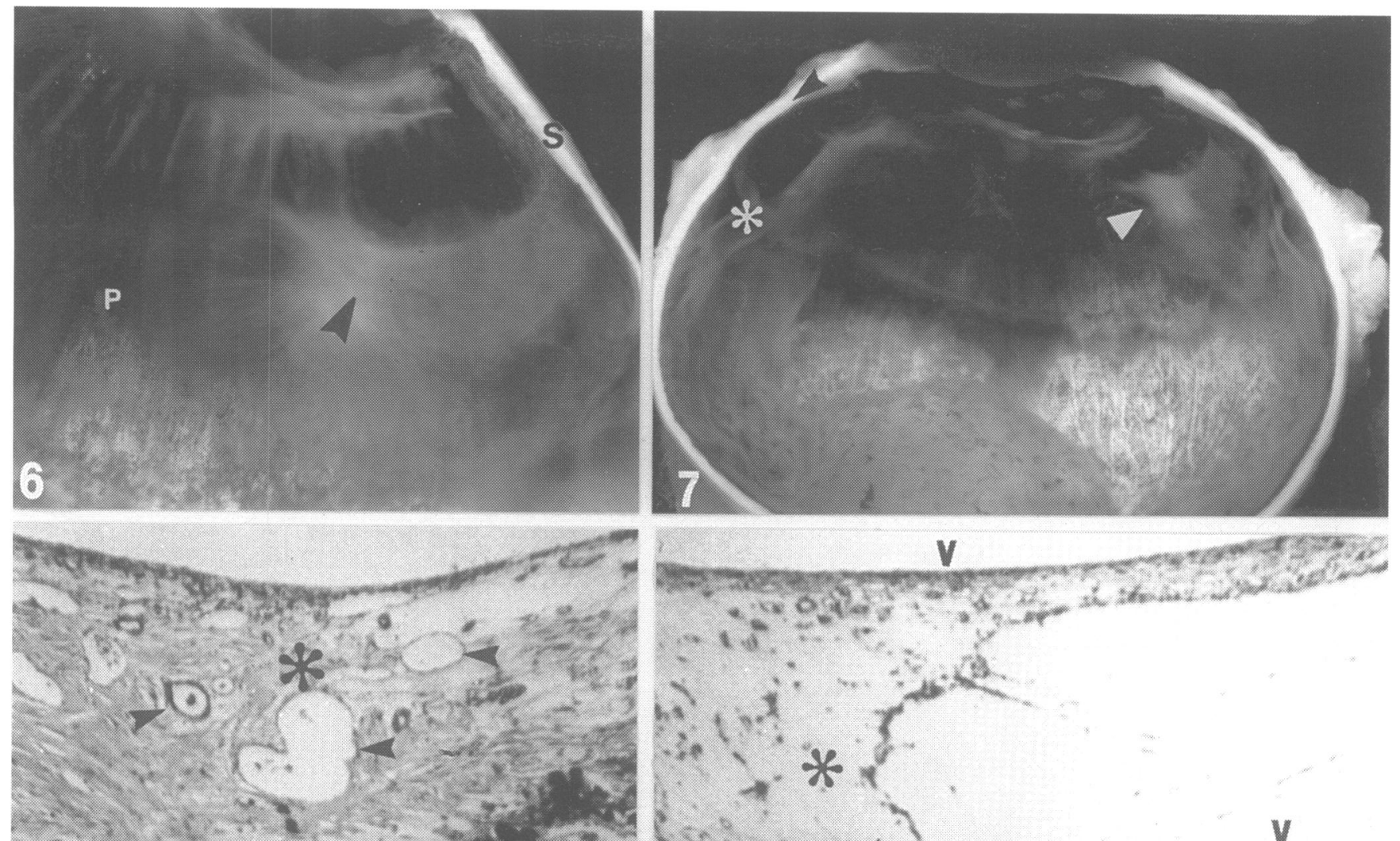

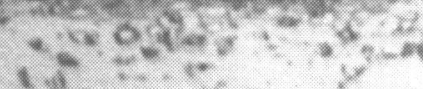

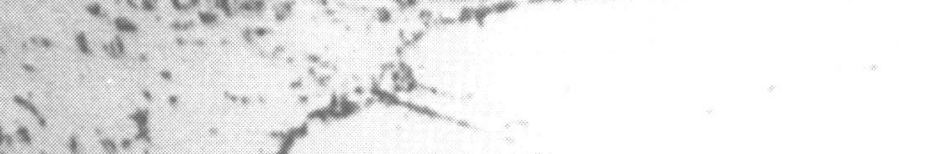

$\lim _{-\infty} \frac{x}{4}$
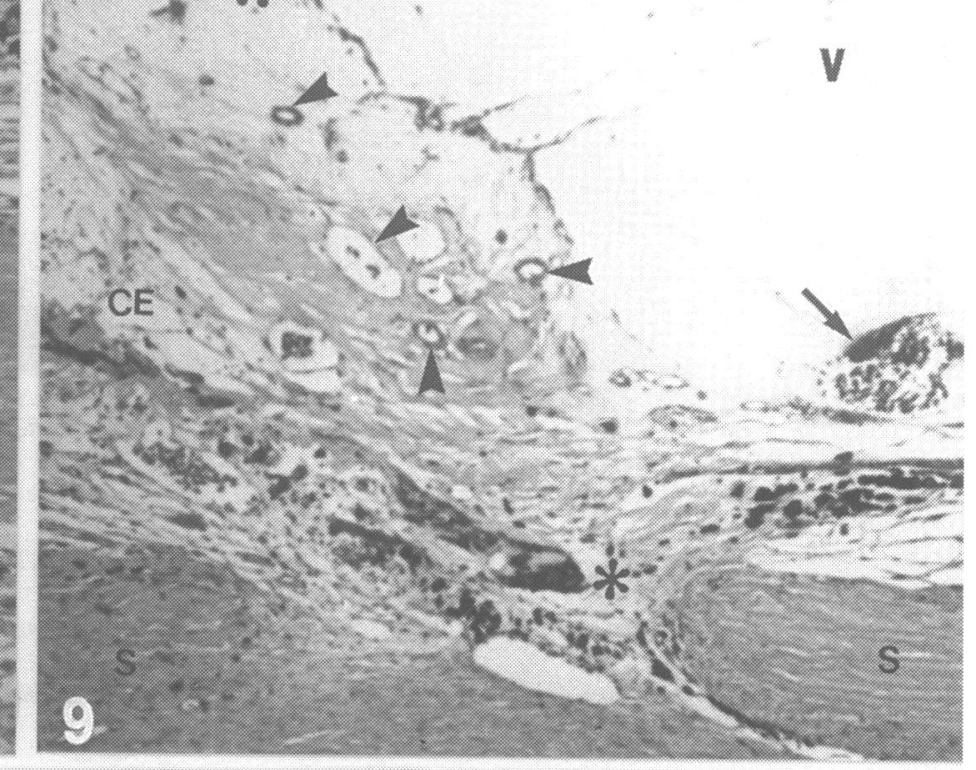

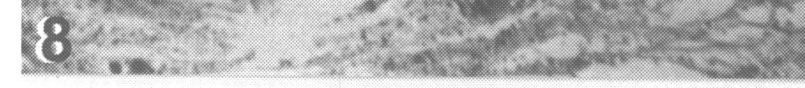

$+2$
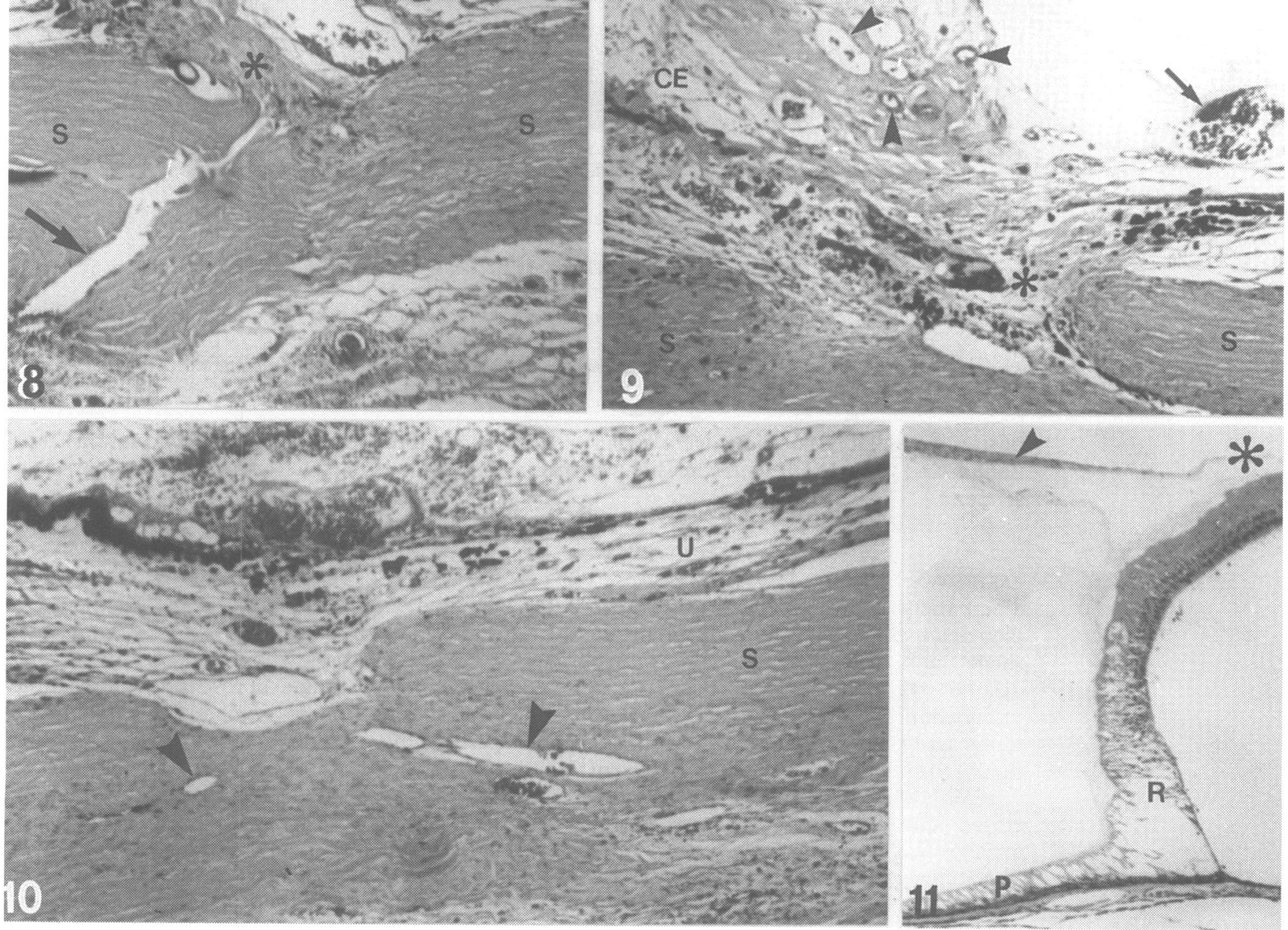

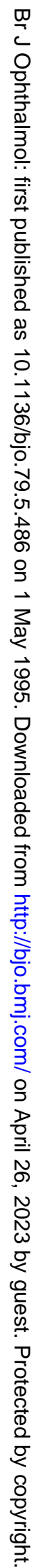

Captions on opposite page. 
Figure 6 The superotemporal, pars plana filtering incision of patient 3 showing a large flat scar spreading along the pars plana (arrowhead). $S=$ sclera, $P=$ pars plana $(\times 10)$.

Figure 7 . The eye of patient 3 showing superotemporal, filtering incision (white arrowhead) and the superonasal incision (black arrowhead). Note the posterior traction causing a peripheral retinal detachment (asterisk) (×3).

Figure 8 The superotemporal, filtering incision in patient 3 showing the open sclerostomy within the sclera (arrow), the fibrovascular tissue occluding the internal opening of the sclerostomy (small asterisk), and the massive accumulation of fibrovascular tissue present in the vitreous (large asterisk) corresponding to the white scar seen grossly. Numerous blood vessels are seen within the scar (small arrowheads). $S=$ sclera, $U=$ uvea (haematoxylin and eosin, $\times 80$ ).

Figure 9 The superonasal vitrectomy incision in patient 3 showing the fibrovascular tissue extending from the sclerotomy (small asterisk) into the vitreous to become continuous with a fibrovascular ingrowth (large asterisk).

The retrolental membrane reaches posteriorly as well along the surface of the residual vitreous. Blood vessels (arrowheads) are present within the ingrowth and vitreous haemorrhage is present (arrow). $S=$ sclera, $V=$ vitreous cavity (haematoxylin and eosin, $\times 80$ ).

Figure 10 The superonasal vitrectomy incision in patient 3 showing blood vessels with the sclera (arrowheads) which could be traced to anastomose with the episcleral vessels and the vessels of the fibrovascular ingrowth. $S=$ sclera, $U=u v e a$ (haematoxylin and eosin, $\times 80$ ).

Figure 11 The peripheral retinal detachment superonasally in patient 3. Fibrovascular tissue (arrowhead) extends posteriorly along the vitreous surface to the posterior aspect of the vitreous base (asterisk) which is pulled forvard to cause a tractional retinal detachment. No blood vessels were noted to extend from the retina into the vitreous base. $R=$ retina, $P=$ pars plana (haematoxylin and eosin, $\times 80$ ).

retrolental scarring and intraocular haemorrhage. The findings were felt to be consistent with the diagnosis of AHFP. One pars plana incision could be identified grossly and it was removed from the specimen with surrounding tissue and postfixed in $2 \%$ osmium tetroxide veronal in cacodylate buffer. After staining with $2 \%$ uranyl acetate and dehydration in acetone, the tissue was embedded in Araldite. Sections were cut with a diamond knife for light microscopy and for electron microscopy after treatment with uranyl acetate and lead citrate.

\section{Results}

Patients 1 and 2 exemplify those findings present early after uncomplicated pars plana vitrectomy in eyes that are normal except for intraocular tumour. At the other end of the spectrum, patients 3 and 4 demonstrate those findings in eyes of patients with end stage diabetes that are removed after vitrectomy.

\section{PATIENT 1}

Significant findings in the first patient were similar in each of the incisions. Superficial scleral apposition was sufficient, but mild to moderate gaping of the internal aspect of the scleral wound was present in certain portions of the incision. The defect in the ciliary epithelium was fairly large in each case as was the gap in the uveal stroma. Ciliary muscle and stroma were fragmented at the wound edge and strands of tissue flowed around the defect in the ciliary epithelium into the vitreous cavity (Fig 1).

Vitreous was incarcerated in the incision and could be seen in the internal aspect of the uveal scleral fissure (Fig 2).

The surrounding uveal stroma showed mild regional congestion and mild focal haemorrhage. Profiles of suture material were present in the mid sclera.

PATIENT 2

The findings in patient 2 , whose wounds were 8 days old, varied from those in patient 1, indicating that the process of repair had begun in the 8 days since vitrectomy.

Scleral apposition was better than in patient 1 and suture profiles were noted in the deep sclera. Only mild gaping of the internal scleral margins was noted centrally. As in patient 1 , a moderate sized gap was noted in the ciliary epithelium (Fig 3). This region was filled with numerous cells embedded in an eosinophilic material with slightly fibrillar appearance (Fig 4).

The cells had prominent nuclei and indistinct cell borders except in the vitreous zone, where they became more spindle shaped and appeared to conform to vitreous strands entering the wound area (Fig 5). Cells were noted to stream from the vitreous aspect of the wound into the scleral incision for a short distance (Figs 4 and 5).

Vitreous was adherent to and enmeshed in the scar tissue and cells were growing along fibrils into the vitreous substance (Figs 3 and 5).

\section{PATIENT 3}

In the eye of the third patient there was profuse fibrovascular scarring in the pars plana region, centred around the sclerotomies and extending into the residual collapsed vitreous body. Grossly, the superotemporal wound, where the pars plana filtering operation had been performed, had a flat, white scar reaching from its centre onto the pars plana (Fig 6). The superonasal incision had less severe scarring, but there was contiguous vitreous haemorrhage and traction posteriorly causing a peripheral retinal detachment (Fig 7). The inferotemporal incision had less scarring as well.

Microscopically the superotemporal sclerostomy was open within the sclera, but fibrovascular tissue occluded the opening at the uveal aspect (Fig 8). The other incisions were closed along their entire length. A massive accumulation of fibrous tissue, containing large blood vessels, was present in the vitreous, corresponding to the white tissue seen grossly.

In the superonasal incision (Fig 9) a large gap in the ciliary epithelia was present from which fibrovascular tissue extended internally. The ciliary body and uveal stromal architecture were disorganised in the central scar. More peripherally, where the uveal structure resumed its normal appearance, blood vessels were markedly dilated. Large vascular 


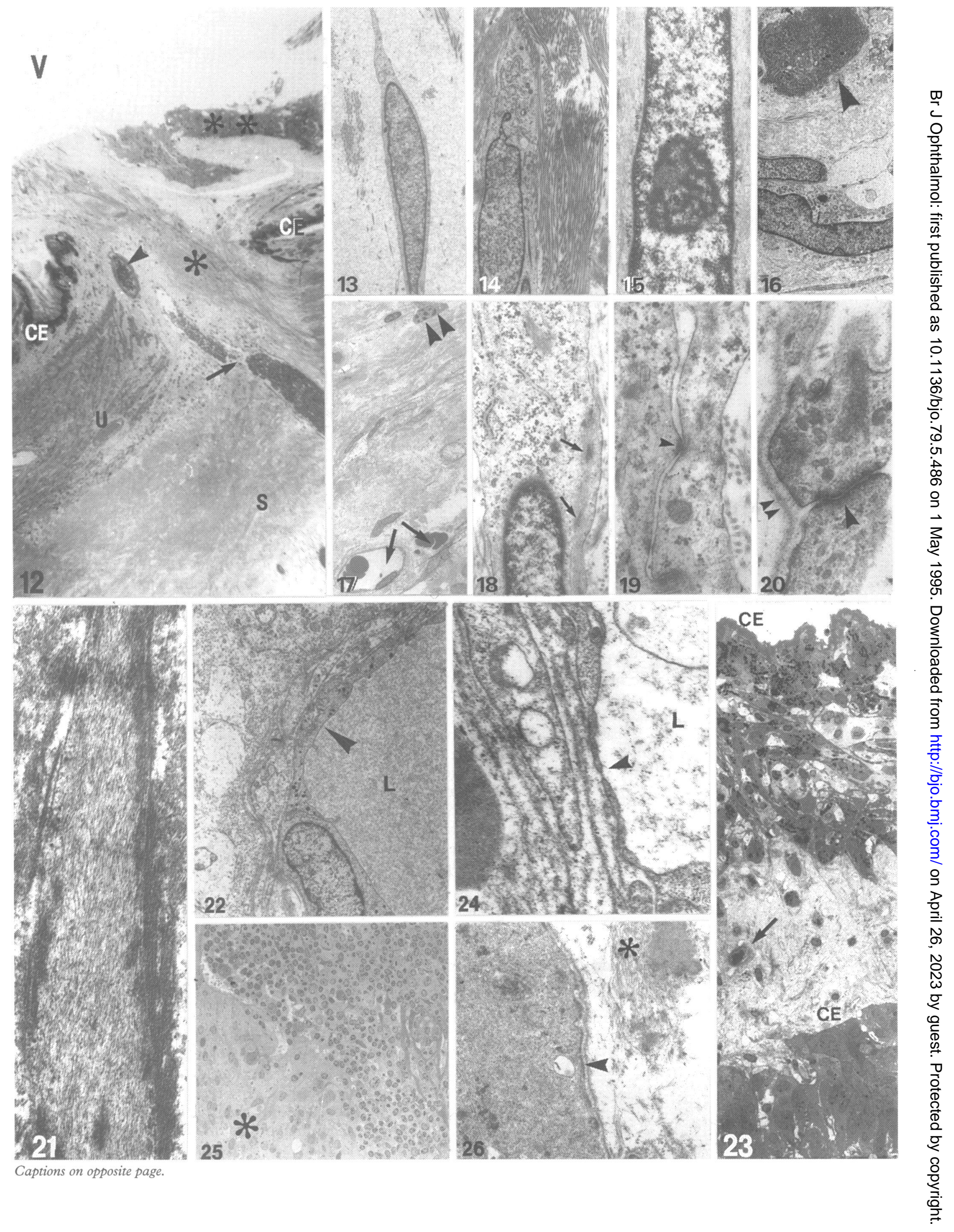


Figure 12 The superotemporal vitrectomy incision of patient 4. Fibrovascular tissue extends as a tract (asterisk) from the episclera into the vitreous cavity through a defect in the ciliary epithelium. A large vein is seen to transit the sclerotomy and connects with episcleral vessels and intravitreous vessels as well (arrow). An artery is also present which anastomoses with vessels in the ciliary body (arrowhead). Proliferating ciliary epithelium is present in the vitreous at the posterior aspect of the incision (double asterisk). $S=$ sclera, $U=u v e a, C E=$ ciliary epithelium, $V=$ vitreous (methylene blue, $\times 50$ ).

Figure 13 A fibroblast in loose collagen from the episcleral tissue of patient 4 (electron microscopy, $\times 3000$ ).

Figure 14 The intrascleral portion of the incision consisted of bundles of collagen and fibroblasts running parallel to the axis of the wound (electron microscopy, $\times 3000)$.

Figure 15 A single myofibroblast was noted in the subepithelial portion of the scar (electron microscopy, $\times 12000$ ).

Figure 16 The intravitreous portion of the scar contained fibroblasts and plasma cells (arrowhead) (electron microscopy, $\times 2200$ ).

Figure 17 The posterior aspect of the vitreous scar, lying next to the ciliary epithelium contained capillaries (arrows), plasma cells (double arrowhead), and fibrous tissue (electron microscopy, $\times 700$ ).

Figure 18 Myofibroblasts were present in the posterior aspect of the vitreous scar and contained prominent rough endoplasmic reticulum and intracytoplasmic fibrils (arrows) (electron microscopy, $\times 12000$ ).

Figure 19 Desmosomes were noted between adjacent myofibroblasts (arrowhead) (electron microscopy, $\times 20000$ ).

Figure 20 functional complexes (arrowhead) and basement membrane formation (double arrowhead) were prominent features of the epithelium cells (electron microscopy, $\times 30$ 000).

Figure 21 Degenerating myofibroblasts were noted in the vitreous scar anterior to the incision in patient 4 (electron microscopy, $\times 8800$ ).

Figure 22 Blood vessels located in the central portion of the anterior vitreous scar did not show endothelial fenestrations (arrowhead). L=lumen of vessel (electron microscopy, $\times 4400$ ).

Figure 23 The ciliary epithelia in the anterior region were separated into two layers by a zone of loose connective tissue. $C E=$ ciliary epithelium vessel (arrow) (electron microscopy, $\times 300$ ).

Figure 24 The vessels in the loose connective tissue exhibited pores in the endothelium (arrowhead). L=lumen of vessel (electron microscopy, $\times 20000)$.

Figure 25 Sheets of epithelial cells (asterisk) extended centrally into the inflammatory cells in the retrolental portion of the vitreous (electron microscopy, $\times 250$ ).

Figure 26 The epithelial cells had basement membrane material on their free surface (arrowhead) along with an abundance of fibrils (asterisk) (electron microscopy, $\times 12000)$.

channels in the sclera were noted which could be traced to the vessels in the sclerotomy scar and to vessels in the episclera (Fig 10).

The remaining vitreous was collapsed markedly and was drawn anteriorly to become continuous with a retrolental membrane. The posterior aspect of the vitreous base was pulled forward, causing the peripheral retina to detach (Fig 11). The subjacent peripheral choroid was also detached. No blood vessels were identified to arise from the peripheral retina nor were vessels seen to enter the residual lens capsule. Fibrovascular tissue from the sclerotomy extended into the vitreous to become a part of the retrolental scar.

\section{PATIENT 4}

Light microscopy of serial sections through the superotemporal vitrectomy incision was carried out (Fig 12). The wound site could be identified easily by the discontinuity in the regular pattern of the scleral fibrils. A stalk of fibrous tissue extended from the episclera into the vitreous cavity through a moderately wide opening in the ciliary epithelium. Here it branched anteriorly and posteriorly. Dilated blood vessels within the ciliary body could be traced to enter the fibrous trunk externally and to course with it into the vitreous scar. A large artery in the vitreous fibrous tissue was found to anastomose with vessels in the ciliary body (Fig 12). In the centre of the scar a large vein was followed from the vitreous cavity through the stalk and through the sclerotomy to the episcleral blood vessels. At this point fibrous tissue from the episclera could be seen to stream along the walls of the vein, through the sclerotomy, and into the substance of the intraocular fibrous trunk (Fig 12).

Electron microscopic examination concentrated on several areas of interest: the episcleral tissue, the intrascleral portion of the incision, and the tissue within the vitreous cavity.

The episcleral tissue external to the incision consisted of mature collagen and fibroblasts arranged in a less regular, looser pattern (Fig 13).

The intrascleral portion of the incision consisted mainly of bundles of collagen, generally running parallel to the axis of the wound (Fig 14). The collagen had the characteristic $64 \mathrm{~nm}$ banding of type I (adult) collagen. Embedded in the fibrils were mature appearing fibroblasts (Fig 14). A single myofibroblast, generally resembling a fibroblast but with prominent myofibrils and rough endoplasmic reticulum, was seen in the subepithelial portion of the scar (Fig 15). The electron microscopic features of the large artery and vein which accompanied the intrascleral scar were unremarkable in that they resembled the structure of normal, similar sized vessels.

In the intravitreous portion of the lesion gap of ciliary epithelia, the fibrous tissue became more cellular as it fanned out onto the surface of the ciliary body. Fibroblasts and plasma cells were present (Fig 16). Posteriorly, in the layer of scar lying next to the ciliary epithelium (Fig 17), myofibroblasts were present with axially oriented intracytoplasmic fibrils and prominent rough endoplasmic reticulum (Fig 18). In places discontinuous basement membrane material was present and desmosomes were seen (Fig 19). A few capillaries with non-fenestrated endothelium were present (Fig 17). Collagen structure was similar to that noted deeper in the wound, and scattered plasma cells were present (Fig 17). Nearer to the vitreous cavity there was a collection of epithelial cells in the fibrous scar. These cells had prominent nuclei, abundant cytoplasm, basement membranes, organelles, and cellular junctions typical of epithelial cells (Fig 20).

Anterior to the wound the vitreous cavity was more infiltrated with fibrocellular tissue and the ciliary epithelia were more distorted and displaced vitread. The density of fibrocellular material was greatest just behind the lens, and small pockets of inflammatory cells 
were present. Fixation in this region was poorer than in the rest of the specimen, suggesting that degeneration or necrosis of tissue had occurred. At higher magnification, areas of fine fibrils, most probably collagen, were seen to intermingle with elongated structures containing microfilaments inserting into dense plaques (Fig 21). More centrally, varying amounts of clear matrix and fine fibrils were present containing vascular structures. These vessels did not show fenestrations (Fig 22).

The ciliary epithelia in this anterior region were displaced vitread and separated into two layers. Between these was a zone of loose connective tissue in which vessels were present (Fig 23). The vessels in this space exhibited pores (Fig 24). The origin of these vessels could not be determined. The non-pigmented ciliary epithelium was contiguous with sheets of cells extending into the inflammatory tissue within the vitreous cavity (Fig 25). These were arranged in multiple layers in some places, and where they had a free surface, basement membrane material was present along with an abundance of fibrils (Fig 26).

\section{Discussion}

A number of reports on the pathology of eyes enucleated after vitrectomy have appeared in the literature. ${ }^{1-11}$ Some authors have indicated that their specimens showed limited changes at the site of the pars plana incision and were not associated with excessive ingrowth of tissue into the vitreous cavity. ${ }^{34-6910}$ Others, however, have noted early or moderate evidence of fibroplasia from the incision causing significant, or potential, ocular complications. ${ }^{127811}$ One brief report describes the pathology of the wound in a patient who died 3 weeks postoperatively. ${ }^{10}$ It is probable that most eyes enucleated for complications of vitrectomy, or of the underlying disease, have extensive intraocular disorganisation or phthisis bulbi that make them useless in the analysis of the wound sites.

The findings in patients 1 and 2 in this series demonstrate the acute traumatic changes that may occur in creating, using, and closing surgical pars plana incisions. While it is to be expected that some tissue damage might occur, the amount of disruption of the uveal architecture noted here after simple, straightforward vitrectomy is surprising.

Similar findings were demonstrated by Riffenburgh and Roth in their patient who died 3 weeks after vitrectomy for asteroid hyalosis. In their case presence of vitreous in the wound was highlighted by the asteroid bodies, which could easily be seen grossly and histologically. 10

The findings in patients 3 and 4 in this series bring up the issues of fibrous ingrowth and anterior hyaloidal fibrovascular proliferation (AHFP). ${ }^{7-9} 14$ Whereas fibrovascular ingrowth usually is a localised process, AHFP describes a more diffuse process. Fibrous ingrowth and its sequela of retinal detachment and phthisis bulbi have been observed to occur from perforating ocular injuries for many years. ${ }^{16-22}$
Concern over the possibility of this occurring regularly from pars plana incisions was voiced in the early days of vitreous surgery. ${ }^{23} 24$ Fortunately, fibrous ingrowth causing significant intraocular problems after vitrectomy has been rare. ${ }^{12} 25-27$

The term fibrous ingrowth, however, is poorly defined and can cause c $^{225-27}$ confusion. All perforations of the pars plana heal with some degree of fibroplasia or ingrowth of fibrous tissue into the vitreous. ${ }^{1522}$ Therefore, the term fibrous ingrowth should be reserved for those cases in which the scarring causes untoward clinical effects. In addition, although the name seems to imply the growth of fibrous tissue into the eye from the episcleral tissues, the clinically important aspect of fibrous ingrowth is that tissue grows from the eye wall at the site of an injury into the substance of the vitreous and onto its natural surfaces. Because of the normal connections of the vitreous to the retina and ciliary body, especially at the vitreous base, later contraction of this tissue can result in retinal detachment, ciliary body detachment, and phthisis bulbi. Whether or not the scar arises from the episclera or the wound itself is unimportant in this regard; however, there is a tendency for clinicians to think that poor wound healing or evidence of tissue entering the eye from without is necessary to establish the diagnosis of fibrous ingrowth. On the contrary, the scleral portion of a sclerotomy may be well healed and closed perfectly in the presence of profuse ingrowth or outgrowth from AHFP of fibrovascular tissue from the inner portion of the wound into the surrounding tissues.

Clearly there was excessive fibrous ingrowth of tissue from the routine incision sites as well as from the sclerostomy in patient 3 (Figs 6 and 7). As expected, there was vitreous haemorrhage and traction retinal detachment. The communication of blood vessels from the episclera into the intraocular fibrous tissue was obvious. Despite the confounding changes wrought by the cyclitic membrane and phthisis bulbi, the eye of patient 4 also had excessive fibrous ingrowth (Fig 12). Again the transit of blood vessels through the incision was readily apparent.

Communication of blood vessels through defects in the sclera was observed in monkey experiments even in simple 25 gauge needle incisions; therefore it is not surprising to see blood vessels transiting the incision site in these two eyes. ${ }^{12}$ Such observations alone are not evidence that episcleral tissue has invaded the eye. Nevertheless, the present two cases (cases 3 and 4) show that the scleral defect created at the time of surgery can be a pathway for vascular channels to communicate with an intraocular process. Certainly, if the process is active, the vessels might be dilated and visible clinically. This clinical finding has been reported previously. ${ }^{1}$

No pathological signs of AHFP - namely, neovascularisation of the anterior retina, were present in patient 3; however, fibrous ingrowth was present. In patient 4 , AHFP was present, and there was also evidence of ingrowth of 
tissue from the sclerotomy site and the presence of blood vessels in the scleral portion of the otherwise well healed incision.

This leaves the question of how fibrous ingrowth and AHFP relate to one another. In their article on the pathology of AHFP, Lewis et $a l^{9}$ stress that the two entities are different clinically and pathologically. In the two eyes that they studied, they found that 'the surgical sclerotomy wounds were well healed without excess proliferative tissue, thereby excluding fibrovascular ingrowth as a cause for fibrovascular proliferation'. 9 As noted above, however, the presence of well healed sclerotomy wounds does not exclude fibrovascular ingrowth. They also found extraretinal neovascularisation in meridians other than those of the sclerotomy sites.

It appears from their findings, and the observations in patients 3 and 4, that clinically significant fibrovascular proliferation in the vitreous base can occur and result in complications such as retinal detachment and phthisis bulbi. Wound healing, evidently contributes variably to the process. There may be instances where excess fibroplasia from healing of the wounds alone is the instigating factor and other times when the wounds are related minimally or only passively. Undoubtedly there is a spectrum between these two extremes where elements of the two processes interact and affect one another. Certainly the pathological phenomena that create the florid anterior proliferation of tissue from the retina in AHFP must have some effect on the healing of sclerotomy incisions, which are located in the same region of the eye. Similarly the injury of tissues located in the immediate proximity of the vitreous base and the processes involved in the healing of these tissues must have some effect on other fibroplastic processes in the vicinity such as AHFP. Numerous studies demonstrate that the cells and blood derived substances involved in the repair process are the major regulators of fibroplasia and vascular proliferation. ${ }^{1328-36}$ These substances and cells are present in abundance in fibrocellular tissue which is in direct contact with the vitreous base, such as that seen in the normal wounds of patient 2 . Furthermore, variations in anatomical closure of the incision and various amounts of vitreous haemorrhage from the wound as seen in patient 1 may have an influence on the extent and duration of the repair process. Finally, underlying ocular disease (diabetes, vascular occlusion) and the other injuries sustained at the time of vitreoretinal surgery (cryotherapy, diathermy, photocoagulation, etc) may also influence the details of healing of the wounds and inflate their importance beyond the usual well contained process that is usually observed. ${ }^{28} 2934$

This work was supported by an award from the Alexander von Humboldt Foundation to AK and was published in part in fulfilment of requirements for membership in the American Ophthalmological Society.

1 Kreiger AE, Straatsma BR, Foos RY. Incisional complications in pars plana vitrectomy. Mod Prob Ophthalmol 1977, 18: 210-23.

2 Puelhorn G, Teichmann $\mathrm{KD}$, Teichmann I. Intraocular plana vitrectomy. Am 7 Ophthalmol 1977; 83: 810-4.
3 Foos RY, Kreiger AE, Nofsinger KD. Pathological study following vitrectomy for proliferative diabetic retinopathy. Retina 1985; 5: 102-6.

4 Buettner H, Machemer R. Histopathologic findings in human eyes after pars plana vitrectomy and lensectomy Arch Ophthalmol 1977; 95: 2029-33.

5 Michels RG. Vitreous surgery. St Louis: Mosby, 1981: 399

6 Weinberg RS, Peyman GA, Apple D. Histopathology after vitrectomy with the vitreophage. Graefes Arch Clin Exp Ophthalmol 1975; 196: 133-42.

7 Elner SG, Elner VM, Diaz-Rohena R, MacKenzie Freeman $\mathrm{H}$, Tolentino FI, Albert DM. Anterior proliferative vitreoretinopathy. Clinicopathologic, light microscopic, and retinopathy. Clinicopathologic, light microscopic, and
ultrastructural findings. Ophthalmology 1988; 95: ultrastruct

8 Elner SG, Elner VM, Freeman HM. The pathology of anterior (peripheral) proliferative vitreopathy. Trans Am Ophthalmol Soc 1988; 86: 330-53

9 Lewis H, Abrams GW, Foos RY. Clinicopathologic features in anterior hyaloidal fibrovascular proliferation after diabetic vitrectomy. Am $\mathcal{F}$ Ophthalmol 1987; 194 614-8.

10 Riffenbaugh RS, Roth AM. Incarceration of asteroid bodies in sclerotomy wound following pars plana vitrectomy. Ophthalmic Surg 1984; 15: 31-3.

11 Kreiger AE, Foos RY, Yoshizumi M. Intravitreous granulation tissue and retinal detachment following pars plana tion tissue and retinal detachment following pars plana injection for cytomegalovirus retinopathy

12 Kreiger AE. The pars plana incision: experimental studies, pathologic observations, and clinical experience. Tran Am Ophthalmol Soc 1991; 89: 549-621.

13 Cleary PE, Ryan SJ. Histology of wound, vitreous, and retina in experimental posterior penetrating eye injury in the rhesus monkey. Am $f$ Ophthalmol 1979; 88: 221-31.

14 Lewis H, Aaberg TM. Anterior proliferative vitreoretinopathy. Am f Ophthalmol 1988; 105: 277-84.

15 Kreiger AE. The pars plana incision: experimental studies, pathologic observations, and clinical experience. Trans Am Ophthalmol Soc 1991; 89: 549-621.

16 Barry DR. Pathological changes after trauma. Trans Ophthalmol Soc UK 1975; 95: 340-8.

17 Eagling EM. Perforating injuries involving the posterior segment. Trans Ophthalmol Soc UK 1975; 95: 355-9.

18 Faulborn J, Topping TM. Proliferation in the vitreous cavity after perforating injury. A histopathologic study. Graefes Arch Clin Exp Ophthalmol 1978; 205: 157-66.

19 Levkoieva ET. The regeneration of wounds of external membranes of the eye in the light of new pathologicoanatomic. Br f Ophthalmol 1947; 31: 336-61.

20 Parsons JH. The healing of wounds of the retina, choroid, and sclera with some remarks on the pathology of 'retinitis proliferans'. Roy Lond Ophthalmol Hosp Rep 1903; 15: 215-53.

21 Winthrop SR, Cleary PE, Minckler DS, Ryan SJ. Penetrating eye injuries. A histopathological review. Br f Ophthalmol 1980; 64: 809-17.

22 Spencer WH. Ophthalmic pathology. An atlas and textbook. Philadelphia: W B Saunders, 1985: 579-81.

23 Kreiger AE, Straatsma BR, Griffin JR, Storm FK, Smiley EH. A vitrectomy instrument in stereotaxic intraocula surgery. Am $\mathcal{F}$ Ophthalmol 1973; 76: 527-32.

24 Gärtner J. In discussion of vitrectomie: instrumentarium und operationstechnik by Buettner $\mathrm{H}$, Machemer $\mathrm{R}$, Parel und operationstechnik by Buettner H, Mache

JM. Ber Dtsch Ophthalmol Ges 1971; 71: 432 .
Brockhurst RJ. Complications of closed vitrectomy. In Freeman H, Hirose T, Schepens CL, eds. Vitreous surgery and advances in fundus diagnosis and treatment. New York Appelton Century Crofts, 1977: 377-85.

26 Tardif YM, Schepens DL, Tolentino FI. Vitreous surgery. $X I V$. Complications from sclerotomy in 89 consecutive cases. Arch Ophthalmol 1977; 95: 229-34.

27 Kreiger AE. Wound complications in pars plana vitrectomy. Retina 1993; 13: 335-44

28 Forrester JV, Lee WR. Cellular composition of posthemorrhagic opacities in the human vitreous. Graefes Arch Clin Exp Ophthalmol 1981; 215: 279-95.

29 Campochiaro PA, Bryan JA, Conway BP, Jaccoma EH. Intravitreal chemotactic and mitogenic activity: implicaIntravitreal chemotactic and mitogenic activity: implica-
tion of blood-retinal barrier breakdown. Arch Ophthalmol tion of blood-retinal

30 Campochiaro PA, Gaskin HG, Vinores SA. Retinal cryopexy stimulates traction retinal detachment formation in the presence of an ocular wound. Arch Ophthalmol 1987; 105: 1567-70.

$31 \mathrm{Chen} \mathrm{CH}$, Chen SC. Angiogenic activity of vitreous and retinal extract. Invest Ophthalmol Vis Sci 1980; 19: 596-602.

32 Forrester JV, Docherty R, Kerr C, Lackie JM. Cellular proliferation in the vitreous: The use of vitreous explants proliferation in the vitreous: The use of vitreous explants
as a model system. Invest Ophthalmol Vis Sci 1986; 27:

33 Johnson RN, Olsen K, Hernandez E. Tissue plasminogen activator treatment of postoperative introcular fibrin. activator treatment of postoperat
Ophthalmology 1988; 95: 592-6.

34 Raymond L, Jacobson B. Isolation and identification of stimulatory and inhibatory cell growth factors in bovine vitreous. Exp Eye Res 1982; 34: 267-86.

35 Sen HA, Robertson TJ, Conway BP. The role of breakdown of the blood-retinal barrier in cell-injection models of proliferative vitreoretinopathy. Arch Ophthalmol 1988; 106: $1291-4$.

36 Vidaurri-Leal JS, Glaser BM. Effect of fibrin on morphological characteristics of retinal pigment epithelial cells. Arch Ophthalmol 1984; 102: 1376-9. 